\title{
A Metafunctional Analysis of the News "ROK, DPRK Agree to Defuse Tension after Talks" on China Daily
}

\author{
Bo $\mathrm{Xu}^{1}$ \\ ${ }^{1}$ School of Foreign Languages, Leshan Normal University, Leshan, Sichuan, China \\ Correspondence: Bo Xu, School of Foreign Languages, Leshan Normal University, Leshan, Sichuan, China. Tel: \\ 86-15228171918. E-mail: 419934369@qq.com
}

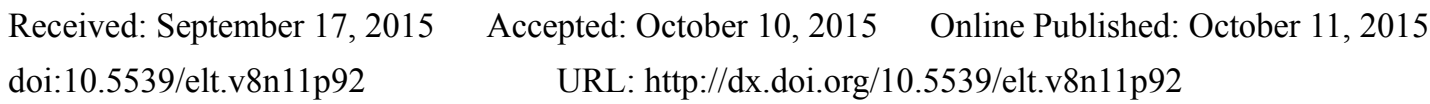

\begin{abstract}
On the basis of the three metafunctions in Systemic Functional Linguistics (SFL): experiential, interpersonal and textual, the paper makes an analysis of the current news "ROK, DPRK Agree to Defuse Tension after Talks" on China Daily. The paper finds out that the political news has unique features in terms of experiential, interpersonal and textual function. Objectivity and accuracy of network news is realized via transitivity systems and third person pronoun in the news.
\end{abstract}

Keywords: systemic functional linguistics, metafunctions, current news, features

\section{Introduction}

With the advent of $21^{\text {st }}$ century, information globalization enables the Internet to develop rapidly. Internet has become one of the news media nowadays. Convenience, rapidity and accuracy of internet news have been accepted by the audience worldwide. Since 1980s, English media has been gradually internationalizing, which has exerted great impact on Chinese news media, internet in particular. Due to the English dominant situation in the world, China is developing its English media, especially English network news. English network news is one of the media in Chinese publicity to foreigners, the window for foreigners to learn about China. Thus, English networks news plays a vital role in the process of understanding China.

Being a special text, English network news has its unique features. It is necessary that we should study the features of English network news. Based on the three metafunctions put forward by Halliday (Halliday, 2000) in his famous book An Introduction to Functional Grammar, the paper selects one piece of news named "ROK, DPRK Agree to Defuse Tension after Talks" on China Daily (August 25, 2015) as corpus to make an analysis from the perspective of experiential, interpersonal and textual function.

\section{Literature Review}

Scholars both in China and abroad conduct relevant researches on English network news from different perspectives. In foreign countries, Van Dijk (1988a) makes an analysis of 700 pieces of news report on 138 newspapers from 99 countries and he draws the conclusion that news schemata and macro-rules will have great impact on news discourse analysis.

Van Dijk (1998b) does a systematic study of structure, composition and acceptance of news. He makes an assumption that news discourse has a standard structure or news schemata to organize news report: the beginning is the well-known headline and lead - they comprise the higher conclusion categories such as event, pre-event, background, history and comment. He stresses the fact that news composition is, to some extent, a form of discourse process in which a journalist uses original text to compose news report.

In China, many scholars conduct research on news text from different perspectives. Based on a theoretical discussion and the steps of discourse analysis, Shan Sheng-jiang (2011) makes an analysis of news discourse from the perspective of critical discourse analysis and illustrates it with news discourse analysis. He also points out the issues that need to be paid attention to in order to enhance the quality of news discourse analysis.

Xin Bin (2008) makes a comparison of reporting verbs in news discourse in English and Chinese. He deems that 
analysis of reporting verbs in news discourse surpasses traditional limitation. The focus has been shifted from the direct speech to indirect speech in terms of discourse and pragmatics. The quality and function of reporting speech varies from the genre of the discourse.

Sun Yumei and Sun Zhixiang (2009) give a critically comparative analysis of English news discourse and its Chinese version, using transitivity, with the purpose of revealing the ideological diversity caused by translator during the process of news translation.

$\mathrm{Xu}$ Wenyu (2010) makes an analysis of the differences among sentence beginning, sentence cohesion, argumentative tool and textual development mode. He explores the reason that causes the difference, which helps English learner to understand the difference between Chinese and English text in respect of ideology and expression mode.

Based on intertextuality, Lin Gang and Qiu Xuemei (2010) conduct a study on the non-linear feature of network news discourse. They maintain that network news discourse differs from traditional news discourse in non-linear communication, which enables news discourse be filled with intertextuality. The application of hyperlink technology in network news discourse triggers a lot of relevance, making intertextuality be actually realized from original concept.

Xiao Yanlin and Chen Mingfen (2010) interpret network news report from the viewpoint of critical discourse analysis. Xu Bo (2011) makes an analysis of English business letters from the perspective of textual function. Sun Xiaoyan and Yang Tingjun (2014) make a comparison between English and Chinese network neologisms in terms of word-formation and find out that the similar word composition are analogy, abbreviation, homophonic formation and borrowing while English network neologisms adopt blending and coinage.

Weiwei WANG and Weihua LIU (2015) make a critical discourse analysis of news reports on China's bullet-train crash from western media, which reveals the relationship between constructing mode and socio-cultural context. Haiyan Wang (2015) makes a corpus-based contrastive study of online news reports on economic crisis from the perspective of critical discourse analysis.

Scholars both at home and abroad conduct the study of news discourse from the perspective of schemata, discourse analysis, critical discourse analysis, cohesion, intertextuality, transitivity, etc. The researches discussed above have laid a solid foundation and offered new revelation for us. However, a metafunctional analysis of English network news is a new perspective, which offers us a three dimensional perspective to make an analysis of the news discourse.

\section{Theoretical Framework}

Halliday (2000) maintains that child language performs seven basic functions and there is close relationship between language form and function. However, as a child grows into an adult the seven functions are gradually replaced by a more abstract, but also simpler system of functions, and they are the three macro-functions — - the ideational, the interpersonal, and the textual. Experiential function construes a model of experience. Interpersonal function enacts social relationships and textual function creates relevance to context.

Similarly, Thompson (2000/2008) defines them as experiential, interpersonal and textual function. The ideational function is achieved via experiential function and logical function. The experiential function is realized through transitivity and transitivity is achieved through six processes: material process, mental process, relational process, verbal process, existential process and behavioral process. Interpersonal function is achieved through mood, modality, interaction and negotiation; textual function is achieved by thematic structure, thematic progression and cohesion.

The theory of metafunctions is closely related with the other key concepts in SFL such as the theory of system, the theory of register and context, the theory of stratum. And it is in compliance with Halliday's opinion of language, that is, language as social semiotic. The three aspects of metafunctions are the abstract generalizations of language functions and this classification constitutes the framework of SFL. If this classification is broken, the whole picture of systemic functional grammar will be broken and the whole theory of systemic functional linguistics will not be as intact as it is now.

Meanwhile, Halliday (2000) also deems that the aim of constructing Systemic Functional Grammar is to offer a theoretical framework for discourse analysis. The corpus of discourse analysis can be spoken or written. Since English network news is a semantic text, metafunctions theory can be applied to the analysis of English network 
news.

In terms of different criteria, news can be classified into different types. In respect to media, news can be classified into newspaper coverage, magazine coverage, radio news, network news, TV news, cable news, dispatches, etc. As to location, news can be classified into world news, home news, and local news. With regard to contents, news can be divided into political news, economic news, technological news, cultural news, sports news, violence and crime news, disaster news, weather news, obituary, entertainment and so on. The corpus "ROK, DPRK Agree to Defuse Tension after Talks" on China Daily we select is web news, world news and political news. Consequently, it has the common features of objectivity and accuracy.

\section{A Metafunctional Analysis of the News}

According to Halliday (2000:F39), all languages have the three metafunctions: the experiential, the interpersonal and the textual. The experiential function is realized through transitivity; interpersonal function is realized through mood, interaction and negotiation; textual function is achieved by thematic structure and cohesion.

\subsection{Transitivity System in the News}

When it comes to using language, news writer tends to employ objective words rather than subjective words because the news writer needs to express the facts. In this way, the news reader may believe the validity of the news.

When composing the news, news writers are likely to employ accurate and clear language to communicate with the readers. The news writer must try to express his/her meaning clearly so that the reader will understand it well. In order to achieve this, he/she should try to avoid using the words which may cause ambiguity. Both objectivity and clarity are embodied by six processes of transitivity.

In the light of Halliday's (2000) definition of the transitivity system, the paper makes a statistical analysis of the transitivity system of the current news "ROK, DPRK Agree to Defuse Tension after Talks", including clause number and each process's percentage. Through transitivity analysis of the news, the statistics are illustrated in the following table. Illustrated in table1 are the clause number and percentage of the six types of process in the news.

Table 1. Transitivity system in the news

\begin{tabular}{lll}
\hline Types of process & Clause No. & Percentage \\
\hline Material Process & 26 & $79 \%$ \\
Mental Process & 0 & 0 \\
Relational Process & 2 & $6 \%$ \\
Verbal Process & 5 & $15 \%$ \\
Existential Process & 0 & 0 \\
Behavioral Process & 0 & 0 \\
\hline
\end{tabular}

As can be seen from Table 1, material process takes up 79\%; mental process takes up zero; relational process takes up 6\%; verbal process accounts for 15\%; existential process and behavioral process takes up nil.

The fact that material process accounts for the most in the news indicates it is the most frequent use of material process that objectivity is achieved in the news. In the news, the news writer adopts "doing words" such as "agreed", "expressed", "accompanied", to express the action of the entity and form a series of action and steps (i.e. sequences of events). However, mental processes in the news account for zero, which means the news writer doesn't employ any "mental verbs" to convey the writer's idea or opinion. It just expresses the fact. Relational processes takes up $6 \%$ in the news which testify that the writer uses one entity to identify another. Relational processes in the news are to reflect the relationship between the writer and the reader. In this way, accuracy of the news is fully achieved. Behavioral processes account for nil. Verbal process accounts for $15 \%$ in the news. That is to say, verbal processes play a vital role in news. The news writer adopts verbal processes to convey information, for example: "Kim said (verbal process) the ROK side focused, during the dialogue, on winning the 
DPRK's apology and pledge to prevent the recurrence of a series of incidents, including the mine blasts".

Finally, for existential processes, they are not used in the news, but they really count because the use of existential processes reveals the writer's objective attitude.

Objectivity and accuracy of news English interact with each other in the news. If the news writer expresses his/her meaning objectively, clear content of news is conveyed to the reader. If the writer conveys his/her meaning clearly, the reader will get a better understanding of the news. Then, the reader knows the writer's real purpose which requires the writer's objective expression of the news content.

\subsection{Interaction and Negotiation in the News}

When a writer wants to interact with others, he or she will play the part of the speech roles: what he or she says will be regarded as a statement, question, command or offer (Thompson, 2000). By acting out a role, he/she is at the same time creating a corresponding role for the other person (even if the other person does not in turn carry out that role): in asking a question, for instance, the writer creates the role of answerer for the other person. However, the writer may also project a role onto himself or the other person by the way he/she talks about them (ibid.).

Personal pronouns are usually used to tell interpersonal relationships between or among the individuals involved in interaction (Zhang, 2006). News writers can use different kinds of pronouns to indicate their attitudes and relationships to readers in their texts, presenting statements subjectively, interactively, or objectively. Personal pronouns in the basic grammatical distinctions are those used to indicate first or second or third person. $I$ indicates the individual who utters the text; you refers to the individual addressed in the present instance of text; the third person pronouns (he, she, it, they), unlike the first or second pronoun, refer to the other party or parties in the situation but not the participants in the speech event (ibid.). Person system in the news is demonstrated in Table 2 .

Table 2. Frequency of personal pronouns in the news

\begin{tabular}{|c|c|c|c|c|c|c|c|c|c|c|c|c|c|c|}
\hline \multirow{2}{*}{ Pronoun } & \multicolumn{5}{|c|}{ First-person } & \multicolumn{2}{|c|}{ Second-person } & \multicolumn{7}{|c|}{ Third-person } \\
\hline & I & me & my & we & us & you & your & he & his & she & her & it & its & they \\
\hline No. & 0 & 0 & 0 & 0 & 0 & 0 & 0 & 0 & 1 & 0 & 0 & 2 & 0 & 1 \\
\hline
\end{tabular}

As can be seem from Table 2 the news writer doesn't use first person pronoun and second person pronoun. Third person pronoun "his", "it" and "they" are used in the news. First, third person pronoun is much more objective than first person pronoun. It is used to describe the news fact. Thus, it is more direct, realer and more convincing. Second, using third person pronoun can better arrange the narration. At last, using third person pronoun to narrate can highlight the focus of the news and struck a chord with the reader.

\subsection{Thematic Structure and Cohesion in the News}

Halliday (2000) maintains that textual function is achieved by thematic structure and cohesion. So, in the following part, thematic structure and cohesion in the news will be discussed.

\subsubsection{Thematic Structure in the News}

Thompson (2008) and Halliday (2000) divide theme types into 7 categories: theme in declarative clauses, theme in wh-questions, theme in yes or no questions, theme in imperative clauses, theme in exclamative clauses, theme in elliptical clauses and theme in clause complex. According to their classification of themes, the author makes an analysis of theme types and also frequency of their use in the news. The following is a table to illustrate theme type in the news. 
Table 3. Theme types in the news

\begin{tabular}{lll}
\hline Types of Theme & Clause number & Percentage \\
\hline theme in declarative clauses & 27 & $79 \%$ \\
theme in WH-questions & 0 & 0 \\
theme in yes/no questions & 0 & 0 \\
theme in imperative clauses & 0 & 0 \\
theme in exclamative clauses & 0 & 0 \\
theme in elliptical clauses & 1 & $3 \%$ \\
theme in clause complex & 6 & $18 \%$ \\
Total & 34 & $100 \%$ \\
\hline
\end{tabular}

As is shown in Table 3, themes in declarative clauses accounting for $79 \%$ are most constantly used in the news. The subject usually works as theme in news. Themes in clause complex take up $18 \%$ in the news. Themes in imperative clauses and themes in yes/no questions account for zero. At the same time, themes in elliptical clauses are also applied in the news. There are no themes in wh-questions and themes in exclamative clauses.

Objectivity of the news is achieved by themes in declarative clauses that are frequently used in the news. In most cases, the theme of the clause is the same as the subject, which is called "conflated". Subject is the theme (Thompson, 2008). Thus, it is called unmarked theme.

Then, themes in clause complex (18\%) are adopted in the news to express topical, interpersonal and textual meaning. The way in which the themes (themes in clause complex) work to signal the "method of development" (Fries, 1981) of the news emerges more clearly if dependent clauses in initial position are taken as the point of departure for the whole clause complex. As regards themes in elliptical clauses, the part of the message is understood from the context.

\subsubsection{Cohesion in the News}

Halliday (2000) divides cohesion into grammatical cohesion and lexical cohesion. Grammatical cohesion is divided into four categories: reference, ellipsis, substitution and conjunction. Lexical cohesion is also divided into four types: repetition, synonymy/antonymy, hyponymy/meronymy and collocation. The author makes an analysis of the grammatical cohesion in the news as follows:

Table 4. Grammatical cohesion in the news

\begin{tabular}{lll}
\hline types of cohesion & number & percentage \\
\hline reference & 6 & $33 \%$ \\
ellipsis & 1 & $6 \%$ \\
substitution & 1 & $6 \%$ \\
conjunction & 10 & $55 \%$ \\
\hline total & 18 & $100 \%$ \\
\hline
\end{tabular}

As is seen from Table 4, reference (accounting for 33\%) is frequently used in the news. The news writer employs person pronoun (his, it, they) and demonstrative pronoun (that) as reference, which embodies the objectivity of the news. In the news the writer adopts ellipsis to establish a rapport that is not semantic but lexicogrammatical, a relationship in the wording rather than in the meaning. Substitution is an important device, showing omission and grammatical function (Halliday, 2000). Conjunction, which accounts for $55 \%$ of the total grammatical cohesion, is most frequently employed in the news, showing extension and enhancement.

Subsequently, the author makes an analysis of the lexical cohesion in the news as follows: 
Table 5. Lexical cohesion in the news

\begin{tabular}{lll}
\hline Types of cohesion & Number & Percentage \\
\hline repetition & 3 & $9 \%$ \\
synonymy/antonymy & 6 & $19 \%$ \\
hyponymy/meronymy & 1 & $3 \%$ \\
collocation & 22 & $69 \%$ \\
Total & 32 & $100 \%$ \\
\hline
\end{tabular}

The remaining type of pattern by which a writer creates cohesion in discourse is the choice of lexical items (Halliday, 2000). Lexical cohesion comes up through selecting relevant items that have appeared.

As is illustrated in table 5, collocation is most frequently used in the news. Synonymy or antonymy is frequently employed in the news. Repetition which is the most direct form of lexical cohesion, together with hyponymy or meronymy is seldom used in the news.

\section{Conclusion}

As discussed above, the paper chooses one piece of news named "ROK, DPRK Agree to Defuse Tension after Talks" on China Daily (August 25, 2015) as the corpus to make an analysis from the perspective of transitivity, interaction and negotiation, thematic structure and cohesion. The news itself is world political news. Thus, it shares the salient features of objectivity and accuracy.

Objectivity and accuracy, being the salient features of political web news, is realized via transitivity systems and third person pronoun in the news. Meanwhile, objectivity of the network news feature is also realized through themes in declarative clauses that are most frequently employed in the news. Thematic structure and cohesion, being the embodiment of the textual function, breathes relevance into the transitivity and interpersonal function.

\section{Acknowledgments}

This paper is supported by a grant from "Web Culture Project Sponsored by the Humanities and Social Science Research Base of the Sichuan Provincial Education Department" (Project name: Functional Discourse Analysis of Chinese and American English Web News; Project number: WLWH15-24).

\section{References}

Fries, P. H. (1981/1983). On the Status of Theme in English: Arguments from Discourse. In J. S. Petofi, \& E. Sozer (Eds.), Micro-and Macro-Connexity of Discourse. Hamburg: Helmut Buske.

Halliday, M. A. K. (2000). An Introduction to Functional Grammar (2nd ed.). London: Edward Arnold/ Beijing: Foreign Language Teaching and Research Press.

Halliday, M. A. K. (2007). Linguistic Studies of Text and Discourse. Beijing: Peking University Press.

Haiyan, W. (2015). A Corpus-based Contrastive Study of Online News Reports on Economic Crisis -- A Critical Discourse Analysis Perspective. Journal of Language Teaching \& Research, 3, 627-632.

Lin, G., \& Qiu, X. (2010). Intertextuality and the Non-linear Feature of Network News Discourse. Writer Magazine, 4, 141-142.

ROK, DPRK Agree to Defuse Tension after Talks. Retrieved from http://europe.chinadaily.com.cn/world/2015-08/25/content_21695846.htm

Shan, S.-J. (2011). Critical Discourse Analysis of News Discourse. Foreign Language Research, 6, 78-81.

Sun, Y., \& Sun, Z. (2009). Critically Comparative Analysis of English and Chinese News Discourse from the Transitivity Perspective. Journal of Guizhou University (Social Science), 1, 113-117.

Sun, X., \& Yang, T. (2014). A Comparative Study of Word-formation between English and Chinese Network Neologisms. Modern Chinese, 2, 157-160.

Thompson, G. (2008). Introducing Functional Grammar (2nd ed.). London: Hodder Arnold.

Van Dijk, T. A. (1988a). News Analysis: Case Studies of International and National News in the Press. Hillsdale, 
NJ: Lawrence Erlbaum.

Van Dijk, T. A. (1988b). News as Discourse. Hillsdale, NJ: Erlbaum.

Wang, W., \& Liu, W. (2015). Critical Discourse Analysis of News Reports on China's Bullet-Train Crash. Studies in Literature and Language, 2, 42-49.

Xiao, Y., \& Chen, M. (2010). An Empirical Analysis of the Relations between Discourse and Social Power. Journal of Yang- tze University (Social Sciences), 8, 261-262.

Xin, B. (2008). A Comparative Analysis of the Reporting Verbs in China Daily and the New York Times. Journal of Sichuan International Studies University, 3, 61-65.

Xu, B. (2011). On Textual Function of English Business Letters. Overseas English, 6, 352-354.

Zhang, T. (2006). A Study of Interpersonal Meaning in Academic Papers. Qingdao: China Oceania University Press.

\section{Copyrights}

Copyright for this article is retained by the author(s), with first publication rights granted to the journal.

This is an open-access article distributed under the terms and conditions of the Creative Commons Attribution license (http://creativecommons.org/licenses/by/3.0/). 